OPEN ACCESS

Edited by:

Carl-Otto Ottosen,

Aarhus University, Denmark

Reviewed by:

Daniel A. Jacobo-Velázquez, Monterrey Institute of Technology and Higher Education (ITESM), Mexico Xiaoguang Sheng ZheJiang Academy of Agricultural Sciences, China

*Correspondence: Houcheng Liu liuhch@scau.edu.cn

Specialty section: This article was submitted to Crop and Product Physiology. a section of the journal

Frontiers in Plant Science

Received: 21 October 2021 Accepted: 19 November 2021 Published: 17 December 2021

Citation:

He R, Li Y, Ou S, Gao M, Zhang Y, Song $S$ and Liu H (2021) Regulation of Growth and Main Health-Promoting

Compounds of Chinese Kale Baby-Leaf by UV-A and FR Light. Front. Plant Sci. 12:799376. doi: 10.3389/fpls.2021.799376

\section{Regulation of Growth and Main Health-Promoting Compounds of Chinese Kale Baby-Leaf by UV-A and FR Light}

\author{
Rui He, Yamin Li, Shuying Ou, Meifang Gao, Yiting Zhang, Shiwei Song and Houcheng Liu*
}

College of Horticulture, South China Agricultural University, Guangzhou, China

Chinese kale baby leaves were hydroponically cultured under the basal light (Red: white LEDs $=2: 3$ at PPFD of $\left.250 \mu \mathrm{mol} \cdot \mathrm{m}^{-2} \cdot \mathrm{s}^{-1}\right)$ with different supplemental lighting, including individual ultraviolet-A (UV-A, $\left.380 \pm 10 \mathrm{~nm}, 20 \mu \mathrm{mol} \cdot \mathrm{m}^{-2} \cdot \mathrm{s}^{-1}\right)$, far-red (FR, $735 \pm$ $10 \mathrm{~nm}, 30 \mu \mathrm{mol} \cdot \mathrm{m}^{-2} \cdot \mathrm{s}^{-1}$ ) light, and their combination (UF) radiation in an artificial light plant factory. Effects of supplemental light qualities on morphology and physiology as well as health-promoting compounds of Chinese kale baby leaves were investigated. Application of UV-A and FR presented a positive effect on biomass, with a pronounced increase in petiole length, stem diameter, main stem length, and leaf area. Notably, plants under UF grew more vigorously than under other treatments. Higher levels of FRAP, vitamin C, total phenolic, and flavonoid were observed in plants under UV-A, while no striking changes or a decreasing trend recorded under FR and UF. Moreover, UV-A enhanced the glucosinolates (GLs) accumulation in Chinese kale baby leaves by increasing the predominant GLs (glucoraphanin and glucobrassicin) contents. RTqPCR results indicated that UV-A upregulated the gene expressions of transcription factors and core structure genes related to GLs biosynthesis. However, downregulated or unchanged gene expressions of GLs biosynthesis-related genes in Chinese kale baby leaves were observed in FR and UF. Therefore, UV-A was benefited for the production of functional substances, while FR was conducive to a significant increase in crop yield. The combination of UV-A and FR, as a balance between yield and production of secondary metabolite, provided a new perspective for the application of artificial light in horticultural crop production.

Keywords: UV-A, far-red light, Brassica alboglabra, glucosinolate, metabolism

\section{INTRODUCTION}

Light not only provides energy for plant photosynthetic, but it is also the most indispensable environmental signal to trigger an ensemble of signal-transducing photoreceptors that regulate plant growth, development, and metabolism (Karpiński et al., 2013). Plants respond to different light environment via multiple types of photoreceptors, including red and far-red light receptor phytochromes (PHYs), blue and UV-A light receptors cryptochromes (CRYs), phototropins (PHOTs), and Zeitlupe family proteins, as well as UV-B light receptor UVR8 (Galvão and Fankhauser, 2015). Once photoactivated, photoreceptors closely interact with presumably other 
photoreceptors or players, such as HY5, COP1, PIFs (Saijo et al., 2003), regulating plant morphology and a metabolite across an entire plant life cycle.

Light-emitting diode lights have been widely applied to horticultural cultivation to increase biomass production and nutritional quality, with numerous advantages over traditional light sources (Qian et al., 2016; Holopainen et al., 2018; Jung et al., 2021). Various focuses were given on photosynthesis, morphology, yield, and phytochemical accumulation of vegetables affected by red and blue light radiation due to that these spectral regions efficiently absorbed by chlorophyll. Ultraviolet-A (UV-A) light and far-red (FR) light, kinds of invisible lights, have created new opportunities to alter plant morphological and physiological properties, which depend on their wavelengths, intensities, and irradiation time (Fukuyama et al., 2017; Li et al., 2020a; Zhang et al., 2020; He et al., 2021).

Impacts of UV-A radiation on various aspects of vegetative and reproductive growth, as well as secondary metabolites accumulation, have been intensively investigated in recent years. Generally, conclusions that UV-A was beneficial for phytochemicals production, in particular of phenolics and flavonoids, have well been drawn (Neugart and Schreiner, 2018), but it is still limited about the effects of UV-A on plants growth. Stimulatory effects on biomass production and morphology were found under UV-A supplementation in tomato seedlings (MarizPonte et al., 2018), kale (Lee et al., 2019), and lettuce (Chen et al., 2019). However, a $10 \mu \mathrm{mol} \cdot \mathrm{m}^{-2} \cdot \mathrm{s}^{-1} \mathrm{UV}$-A (380 nm) supplement exerted an inhibitory effect on fresh and dry weight of "Red butter" lettuce, whereas no significant difference in "Yanzhi" plants (He et al., 2021).

Far-red (FR) light plays crucial roles in a wide range of physiological responses in plants, including stem length and leaf elongation, leaf area expansion, leaf moving upward, biomass increases or decreases (Legendre and van Iersel, 2021). FR $\left(740 \mathrm{~nm}, 30 \mu \mathrm{mol} \cdot \mathrm{m}^{-2} \cdot \mathrm{s}^{-1}\right)$ supplementation increased plant biomass of two lettuce cultivars, yielding greater leaf length, leaf width, fresh and dry weight (He et al., 2021). Similarly, plant dry mass, fruit number per plant, and average fruit fresh weight in tomato were significantly increased by supplemental FR (Ji et al., 2020).

Chinese kale (Brassica alboglabra Bailey) is a widely consumed vegetable in China and Southeast Asia, which is a rich source of antioxidants and anticarcinogenic compounds, including vitamin C, glucosinolates (GLs), and phenolic compounds. Glucosinolates are sulfur and nitrogen-containing secondary metabolites in the Brassicaceae family, functioning as powerful antioxidants. The active hydrolysed by-products, isothiocyanates, which are degradation products of GLs breakdown by myrosinases, are beneficial to humans in preventing types of diseases, such as cancer, inflammation, and some degenerative diseases (Kapusta-Duch et al., 2012). UV-A radiation at different light intensities or wavelengths was in favor of GLs accumulation in mature plants of red-leaf and green-leaf pak choi (Tang et al., 2020), baby leaves of Chinese kale and pak choi (Li et al., 2020b), as well as broccoli sprouts (Gao et al., 2021), while FR seemed to be a negative factor in GLs accumulation in Brassicaceae vegetables (Steindal et al.,
2016; Li et al., 2021). Supplemental FR was likely more efficient to increase biomass production by enlarging the leaf area and improving the ability of light interception, while it might result in lower phytochemicals contents in plants due to the shade avoidance syndrome (SAS) induced by FR light (Li et al., 2020a; He et al., 2021). Indeed, UV-A was beneficial for phytochemicals production, in particular of health-promoting compounds (Neugart and Schreiner, 2018). Although numerous studies have revealed the effects of UV-A or FR alone on vegetative growth, the interactive effect of UV-A and FR on vegetative growth and phytochemicals contents in plants is still limited. The combination of FR and UV-A might as a balance between higher yields and better quality in an artificial light plant factory. The objectives of this study were to quantify the effects of UV-A, FR, and combination of UV-A and FR on the growth and health-promoting phytochemicals in Chinese kale baby leaves.

\section{MATERIALS AND METHODS}

\section{Plant Material and Growth Conditions}

This study was performed in an artificial light plant factory in South China Agricultural University. Three cultivation frames with 6 layers were equally divided into 4 individual experimental units. Shading clothes were placed around the experimental units in order to prevent light interference between treatments. The adjustable LED panels $(150 \times 30 \mathrm{~cm}$; Chenghui Equipment Co., Ltd, Guangzhou, China) with red LEDs $(660 \pm 10 \mathrm{~nm})$, white LEDs (peak at $440 \mathrm{~nm})$, UV-A $(380 \pm 10 \mathrm{~nm})$, and FR $(735 \pm 10 \mathrm{~nm})$ LEDs were used as light sources, which mounted in each cultivation unit in, horizontally, $30 \mathrm{~cm}$ above the cultivation plate.

The Chinese kale (Brassica alboglabra Baile, "Lvbao," from GLseed Co., Ltd, Guangzhou, China) seeds were germinated in a moist sponge block $(2 \times 2 \times 2 \mathrm{~cm})$ and cultured under white LED (300 $\left.\mu \mathrm{mol} \cdot \mathrm{m}^{-2} \cdot \mathrm{s}^{-1}, 12 / 12 \mathrm{~h}\right)$ light after sprouting. Seedlings were fertilized with $1 / 4$ strength Hogland nutrient solution. The composition of the full-strength nutrient solution was presented in Supplementary Table 1. Two weeks later, the seedlings with three expended true leaves were transplanted into a recirculating hydroponic culture system with density of 42 plants per plate $(95 \times 60 \times 3 \mathrm{~cm})$, and three plates containing 126 plants were subjected to each supplemental light treatment described below. The $1 / 2$ strength of the nutrient solution $(\mathrm{pH} \approx 6.5 ; \mathrm{EC} \approx 1.6$ $\mathrm{ms} \cdot \mathrm{cm}^{-1}$ ) was recirculated automatically for $10 \mathrm{~min}$ every half hour.

\section{Supplemental Light Treatments}

A combination of red and white LEDs ( $R: B=2: 3)$ with a light intensity of $250 \mu \mathrm{mol} \cdot \mathrm{m}^{-2} \cdot \mathrm{s}^{-1}$ was used as basal light $(\mathrm{CK})$. The different light treatments were as follows: $20 \mu \mathrm{mol} \cdot \mathrm{m}^{-2} \cdot \mathrm{s}^{-1} \mathrm{UV}-\mathrm{A}$ light added to basal light (UVA), $30 \mu \mathrm{mol} \cdot \mathrm{m}^{-2} \cdot \mathrm{s}^{-1} \mathrm{FR}$ added to basal light (FR), and $20 \mu \mathrm{mol} \cdot \mathrm{m}^{-2} \cdot \mathrm{s}^{-1} \mathrm{UV}-\mathrm{A}$ and $30 \mu \mathrm{mol} \cdot \mathrm{m}^{-2} \cdot \mathrm{s}^{-1} \mathrm{FR}$ added to basal light (UF). The photoperiod was $12 \mathrm{~h}$ per day in all treatments. The light spectral distribution was measured using a spectroradiometer (ALP-01, Asensetek, 


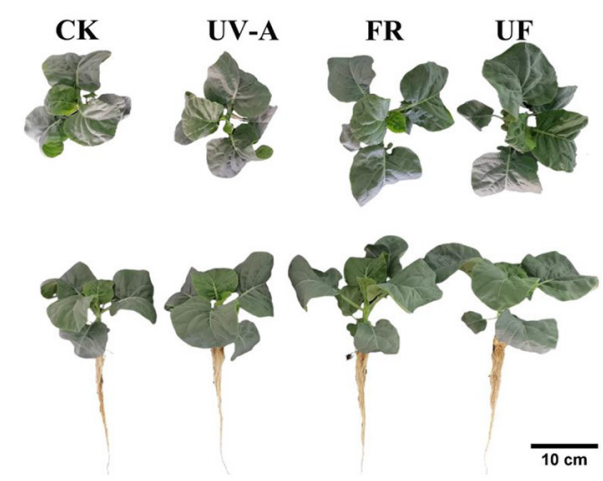

FIGURE 1 | The Chinese kale baby-leaves morphology at 12 days after treatments.

Taiwan) on the Chinese kale baby leave plants canopy level (Supplementary Figure 1).

\section{Morphological Measurements}

Twelve baby-leaf plants per treatment were destructively determined at 3, 6, 9, 12 days after treatment initiation. Shoot (the whole plant without root) and root fresh weight were measured using an electronic balance. Subsequently, shoots and roots of plants were oven-dried separately to a constant mass at $70^{\circ} \mathrm{C}$ for shoot and root dry weight determination. Petiole length of the third true leaf on each plant and main stem length (length from cotyledons to point of growth) using a ruler, while the stem diameter at the widest point of each plant was measured using a digital caliper. The total leaf area was determined using ImageJ 1.42 software (https://imagej.nih.gov/ ij).

The samples used for biochemical analysis and gene expression determinations were collected at 6 th day ( 6 day) under treatments. Three biological repetitions were used in this study. Each biological repetition contained six plants. The shoots of baby-leave plants were immediately frozen in liquid nitrogen and stored at $-80^{\circ} \mathrm{C}$. The morphology of Chinese kale grown with 12 days of lighting treatments is shown in Figure 1.

\section{Phytochemicals Measurements}

The ferric-reducing antioxidant power assay was according to the method decried by Benzie and Strain (Benzie and Strain, 1996). Frozen shoot tissue (about $0.5 \mathrm{~g}$ ) was extracted with $8-\mathrm{ml} 100 \%(\mathrm{v} / \mathrm{v})$ ethanol for $30 \mathrm{~min}$ at $4^{\circ} \mathrm{C}$ in the dark, and then centrifuged at $3,000 \mathrm{rpm}$ for $10 \mathrm{~min}$ at $4^{\circ} \mathrm{C}$. The supernatants $(0.4 \mathrm{ml})$ were mixed with $3.6-\mathrm{ml}$ FRAP reagent [a solution containing a $0.3-\mathrm{M}$ acetate buffer, $10-\mathrm{mM} 2,4,6$ tripyridyl-S-triazine (TPTZ), and $20-\mathrm{mM} \mathrm{FeCl}_{3}$ at a $10: 1: 1$ ratio $(\mathrm{v} / \mathrm{v} / \mathrm{v})]$. Then, the mixture was maintained in a water bath at $37^{\circ} \mathrm{C}$ for $10 \mathrm{~min}$. The absorbance was measured at $593 \mathrm{~nm}$ by UV spectrophotometry.

Total phenolic content was determined according to a FolinCiocalteu assay (Matsuura et al., 2013). Sample extracts were as a FRAP assay above. The 1-ml supernatant was mixed with 0.5 $\mathrm{ml}$ foline-phenol and 11.5-ml 26.7\% (v/v) $\mathrm{Na}_{2} \mathrm{CO}_{3}, 7-\mathrm{ml}$ distilled water. After reacting at $26^{\circ} \mathrm{C}$ for $2 \mathrm{~h}$, absorbance was read at $510 \mathrm{~nm}$ by a UV spectrophotometer.

The total flavonoid content was determined by the aluminum nitrate method (Xie et al., 2015). Briefly, 1-ml extract solution (extracted as FRAP) was added to $11.5 \mathrm{ml} 30 \%$ ethanol and $0.7-$ $\mathrm{ml} 5 \% \mathrm{NaNO}_{2}$. After $5 \mathrm{~min}$, the reaction solution was mixed with $0.7-\mathrm{ml} 10 \% \mathrm{Al}\left(\mathrm{NO}_{3}\right)_{3}$, and $5-\mathrm{ml} 5 \% \mathrm{NaOH}$ was added after further $6 \mathrm{~min}$. The absorbance was measured at $760 \mathrm{~nm}$ using the UV spectrophotometer after $10 \mathrm{~min}$.

The vitamin C (VC) content was determined using the method reported by Kampfenkel et al. (1995). Frozen shoot tissue (0.5 g) was homogenized in $25-\mathrm{ml} 5 \%$ oxalic acid. After filtering, $10-\mathrm{ml}$ extract solution was mixed with 1-ml phosphate-acetic acid, 2-ml $5 \%$ vitriol, and $4-\mathrm{ml}$ ammonium molybdate. The absorbance was recorded at $705 \mathrm{~nm}$ by the UV spectrophotometer.

\section{Minerals Measurements}

The minerals measurement was performed according to Waterland (Waterland et al., 2017). Oven-dried samples power $(0.2 \mathrm{~g})$ was digested with $4-\mathrm{ml} 70 \% \mathrm{HNO}_{3}$ (v:v) for $4 \mathrm{~h}$. The extract was filtered and adjusted to a total volume of $20 \mathrm{ml}$ with deionized distilled water. Mineral concentrations were determined by inductively coupled plasma spectrometry (Optima 2100DV; Perkin Elmer Corp., Waltham, MA, USA).

\section{Glucosinolate Composition and Contents}

Glucosinolate composition and contents were extracted, proposed by previously described by $\mathrm{Li}$, with modifications ( $\mathrm{Li}$ et al., 2021). Freeze-dried samples $(200 \mathrm{mg}$ ) mixed with 4-ml $70 \%$ methanol were kept in water bath $\left(80^{\circ} \mathrm{C}\right)$ for $20 \mathrm{~min}$. The supernatant was collected after being centrifuged at 4,000 rpm for $10 \mathrm{~min}$. The supernatant was transferred into columns filled with 500- $\mu$ l DEAE-Sephadex A-25 (Sigma Chemical Co., Saint Louis, USA), which had been prewashed with 1-ml 6-M imidazole formate and a $0.02-\mathrm{M}$ sodium acetate buffer, respectively. After incubating overnight with $100-\mu 10.1 \%$ arylsulphatase (Sigma, St. Louis, MO, USA), desulphoglucosinolates were eluted with $2-\mathrm{ml}$ distilled water. The total eluate filtered through a $0.22-\mu \mathrm{m}$ membrane filter.

Desulphoglucosinolates were analyzed by HPLC; analyses were conducted on a Waters e2695 liquid chromatograph (Waters Crop., Milliford, MA, USA) with a reversed-phase C 18 column $(5 \mu \mathrm{m}, 250 \times 4.6 \mathrm{~mm}$; Waters SunFire C18, Waters, USA). The column was maintained at $30^{\circ} \mathrm{C}$ and $20-\mu l$ injection volume. A binary gradient was used: $0-32 \mathrm{~min} 0-20 \%$ eluent A; $32-38$ min $20 \%$ A; $39-40$ min $20-100 \%$ A; the eluents were (A) acetonitrile and (B) distilled water, with a flow rate of 1 $\mathrm{ml} \cdot \mathrm{min}^{-1}$. The detection wavelength was recorded at $229 \mathrm{~nm}$. Sinigrin obtained from Sigma (St. Louis, MO, USA) was used as an internal standard for quantitation analysis, and the results were presented as $\mu \mathrm{mol} \cdot \mathrm{g}^{-1} \mathrm{DW}$ (dry weight) of Chinese kale baby leaves.

\section{RNA Isolation and qRT-PCR Analyses}

Total RNA was extracted from $100 \mathrm{mg}$ of frozen tissue using RNAex Pro Reagent (Accurate Biotechnology Co., Ltd., Hunan, China) for three biological repeats. RNA samples, whose 

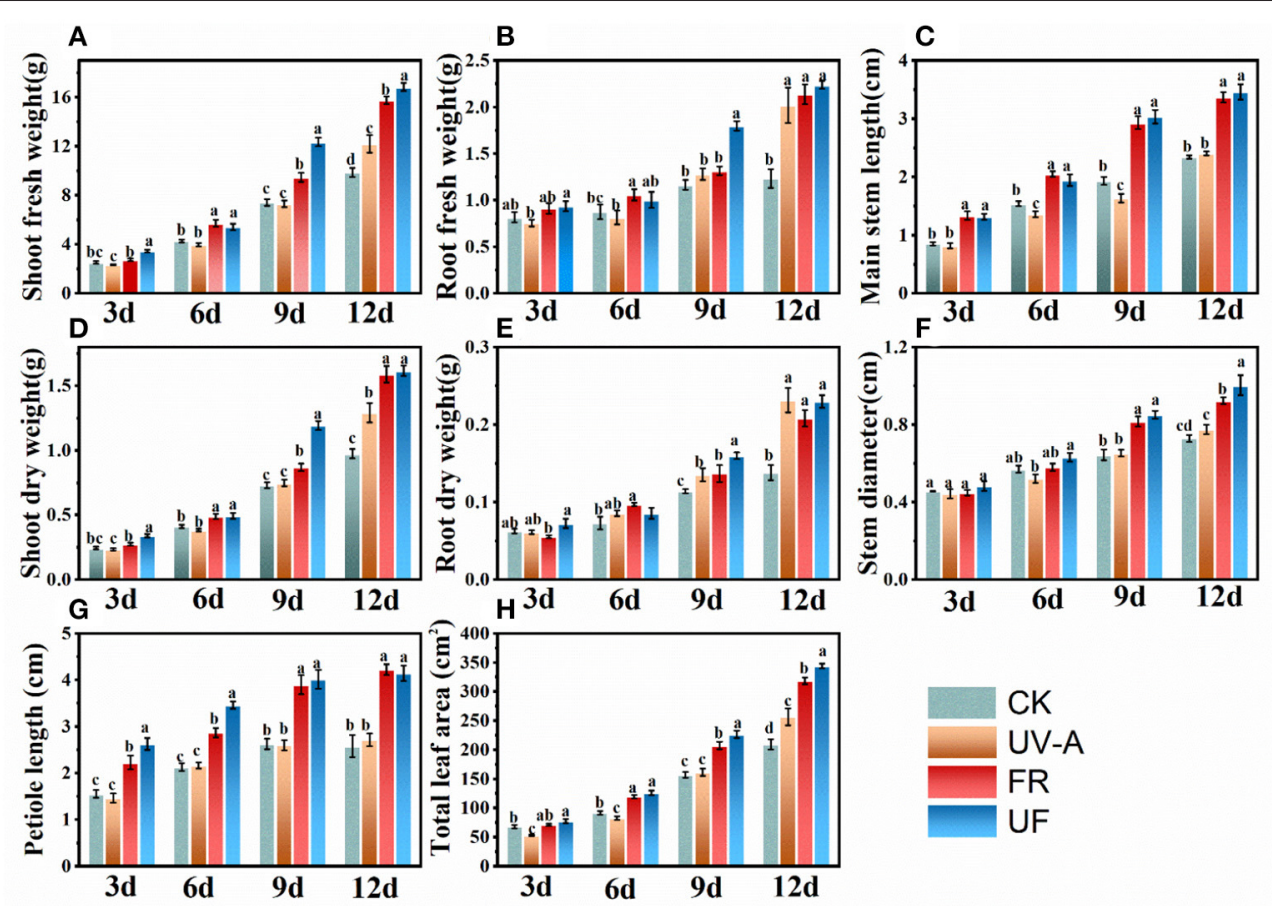

FIGURE 2 | Biometric parameters of Chinese kale baby leaves under different supplementary lightings. Fresh weight of (A) shoot and (B) root. (C) Main stem length. Dry weight of (D) shoot and (E) root. (G) Petiole length of the third leaf. (H) Total leaf area. Different letters on the top of the columns mean significant differences at $p$ $<0.05$ according to Ducan's multiple range test.

OD260/280 and OD260/230 values were within 1.8-2.2, were selected to synthesize complementary DNA (cDNA) using Evo M-MLV RT for PCR Kit (Accurate Biotechnology Co., Ltd., Hunan, China).

Quantitative real time PCR (qRT-PCR) reactions were performed using LightCycler 480 Real-Time PCR system (Roche, Basel, Switzerland) with 10- $\mu$ l Real Time system composed of $5-\mu 1$ TB green (TaKaRa Bio, Inc., Dalian, China), a 1- $\mu$ l cDNA

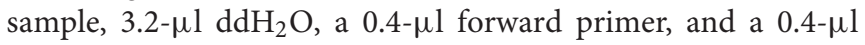
reverse primer. The amplification program consisted of a $30-$ $\mathrm{s}$ initial step at $95^{\circ} \mathrm{C}$, followed by 40 cycles of $5 \mathrm{~s}$ at $95^{\circ} \mathrm{C}$ and $30 \mathrm{~s}$ at $60^{\circ} \mathrm{C}$. The primer sequences used are listed in Supplementary Table 2 . The expression values were normalized with the results of mean values of $e F 1$ the using $2^{-\Delta \Delta \mathrm{Ct}}$ method (Livak and Schmittgen, 2001).

\section{Statistical Analysis}

All values are shown as the means of three replicates with standard error (SE). Analysis of variance was performed by Duncan's multiple range test using the SPSS 22.0 program (SPSS 22.0, SPSS Inc., USA). Different significance of means was tested by LSD at $p<0.05$. Graphs were plotted using Origin 2021 (Origin Lab Corporation, Northampton, MA, United States). The heat map analysis was visualized by TB tools software (Chen et al., 2020).

\section{RESULTS}

\section{Effects of Supplementary UV-A and FR Lights on Plant Biomass and Morphological Properties}

The effects of UV-A and FR radiation on the biometric parameters in Chinese kale baby leaves are presented in Figure 2. UV-A slightly inhibited the growth in Chinese kale baby leaves until 6 days, resulting lower fresh and dry weight and the leaf area. No significant differences of these growth parameters were observed between UV-A and CK at 9 days, while obvious growth promotion effects were found at 12 days. The plants under FR and UF exhibited higher fresh and dry weight than CK from 3 to 12 days (Figures 2A,B,D,E), with a pronounced increase in main stem length (Figure 2C), stem diameter (Figure 2F), petiole length (Figure 2G), and leaf area (Figure 2H).

with a pronounced increase in petiole length, stem diameter, main stem length, and leaf area. Therefore, effects of supplemental UV-A lighting on Chinese kale baby leaves growth depended on the growth stage of plants, where UV-A presented a negative effect on biomass at the early vegetative stage while enhanced the yield at the later stage. UV-A and FR exerted a statistically positive effect on the increase of petiole and main stem length and leaf area, and higher biomass was obtained in the combined UV-A + FR treatment (UF) than under UV-A or FR treatments. 

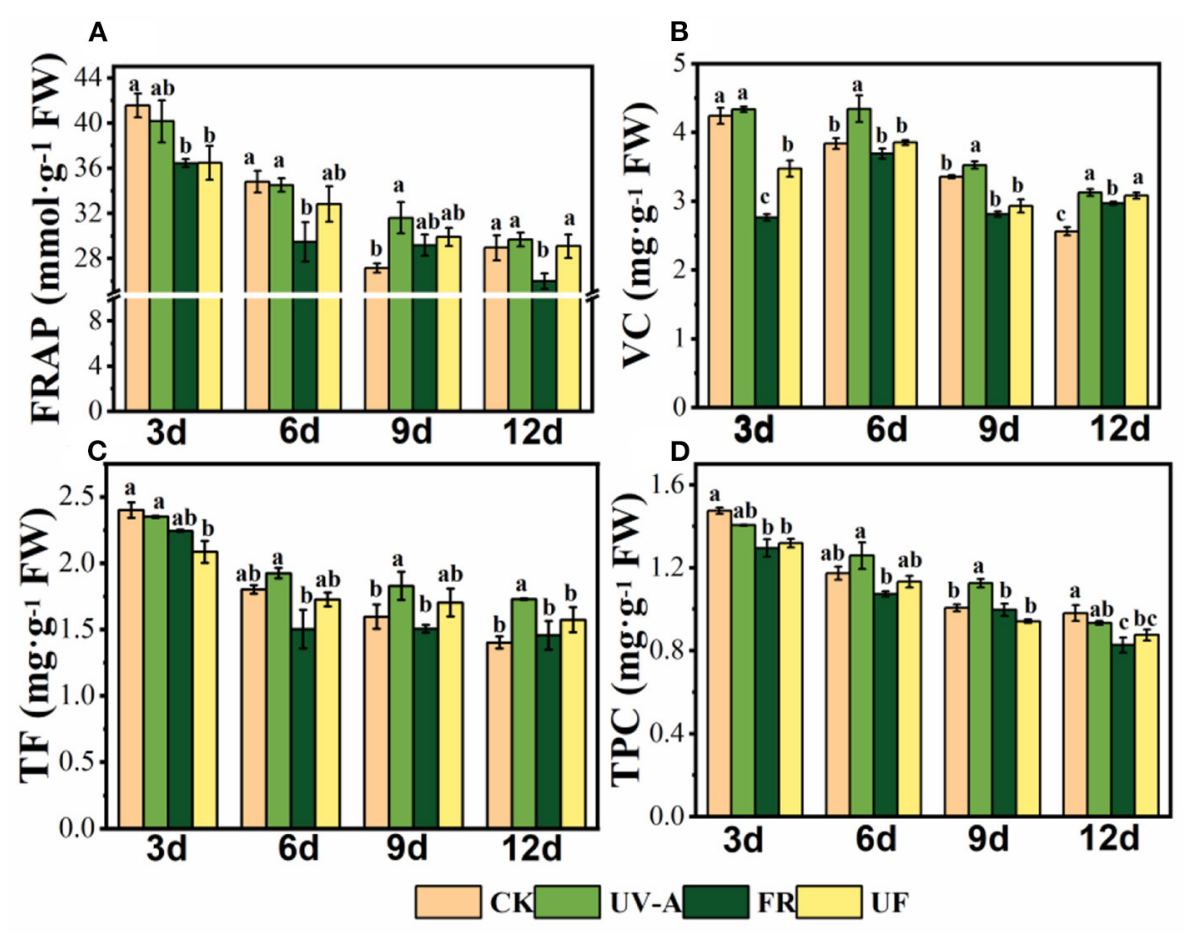

FIGURE 3 | Antioxidant properties of Chinese kale baby leaves under different supplementary lightings. (A) FRAP, ferric ion reducing antioxidant power, (B) VC, Vitamin C, (C) TF, total flavonoids, (D) TPC, total phenolic compounds. Different letters on the top of the columns mean significant differences at $p<0.05$ according to Ducan's multiple range test.

\section{Effects of Supplementary UV-A and FR Lights on the Antioxidant Capacity and Antioxidant Compound Contents of Chinese Kale Baby Leaves}

The antioxidant capacity and antioxidant compound contents of Chinese kale baby leaves decreased gradually with the plant development (Figure 3). FRAP values of Chinese kale baby leaves showed a significantly reduction under FR at 3, 6, and 12 days, while no significant changes were found under UV-A and UF compared with CK (Except that FRAP value was significantly decreased under UF treatment at 3 days) (Figure 3A). The Vc contents in Chinese kale baby leaves significantly increased under UV-A from 6 to 12 days. Also, obvious enhancement of $\mathrm{Vc}$ contents was found in FR and UF at 12 days (Figure 3B). Flavonoids contents under UV-A increased at 6, 9, and 12 days, while no significant changes were found under FR and UF compared with CK. Total polyphenols contents obviously increased under UV-A at 9 days, but no significantly were observed at 3, 6, and 12 days. Moreover, a general trend of a negative effect on polyphenols contents was found in FR and UF compared with CK (Figures 3C,D).

\section{Effects of Supplementary UV-A and FR Lights on Mineral Elements Contents of Chinese Kale Baby Leaves}

There were differences in mineral elements contents in Chinese kale baby leaf shoot tissue at 12 days under supplementary UV-A and FR (Table 1). Contents of N, P, and K exhibited no significant differences among the different lighting supplements except for the $\mathrm{K}$ content increased under FR. Opposite effect was observed in $\mathrm{Ca}$ contents, with a notable reduction in all supplemental treatments. Similar patterns of changes were found in the $\mathrm{Mg}$ and Fe contents, which showed no striking changes in UV-A but a significant decrease in FR and UF. Interestingly, contents of $S$ under UV-A, FR, and UF were prominently higher than under the $\mathrm{CK}$.

\section{Effects of Supplementary UV-A and FR Lights on the Glucosinolates Contents of Chinese Kale Baby Leaves}

Glucosinolates were extracted and analyzed in Chinese kale baby leaves grown under UV-A and FR supplement from 3 to 12 days (Figure 4). Eight GLs were identified by HPLC in Chinese kale baby leaves (Figure 4), which comprised four aliphatic GLs [progoitrin (PRO), glucoraphanin (GRA), sinigrin (SIN), glucobrassicanapin (GNA)], and four indole GLs [4-hydroxy-glucobrassicin (HGBS), glucobrassicin (GBS), 4-methoxy-glucobrassicin (MGBS), and neoglucobrassicin (NGBS)].

There was no significant difference in glucosinolates accumulation in different growth stages (Figure 5). GNA and SIN were the predominant GLs in Chinese kale baby leaves, accounting for 65 and $15 \%$ of the total GLs content, respectively (Figure 5). The largest increase of total and aliphatic GLs was observed in plants exposed to UV-A (Figure 5), mainly 
TABLE 1 | Effects of UV-A and FR on mineral elements contents of Chinese kale baby leaves.

\begin{tabular}{|c|c|c|c|c|c|c|c|}
\hline Treatment & $\begin{array}{c}\mathrm{N} \\
\left(\mathrm{g} \cdot \mathrm{Kg}^{-1} \mathrm{DW}\right)\end{array}$ & $\begin{array}{c}P \\
\left(g \cdot K^{-1} \mathrm{DW}\right)\end{array}$ & $\begin{array}{c}\mathrm{K} \\
\left(\mathrm{g} \cdot \mathrm{Kg}^{-1} \mathrm{DW}\right)\end{array}$ & $\begin{array}{c}\mathrm{Ca} \\
\left(\mathrm{g} \cdot \mathrm{Kg}^{-1} \mathrm{DW}\right)\end{array}$ & $\begin{array}{c}M g \\
\left(g \cdot K^{-1} \mathrm{DW}\right)\end{array}$ & $\begin{array}{c}\mathrm{Fe} \\
\left(\mathrm{mg} \cdot \mathrm{Kg}^{-1} \mathrm{DW}\right)\end{array}$ & $\begin{array}{c}S \\
\left(g \cdot K^{-1} \mathrm{DW}\right)\end{array}$ \\
\hline CK & $52.82 \pm 0.51 a$ & $7.23 \pm 0.14 a$ & $54.99 \pm 0.47 b$ & $29.83 \pm 0.71 a$ & $3.16 \pm 0.02 a$ & $71.50 \pm 4.46 a$ & $10.68 \pm 0.09 c$ \\
\hline UV-A & $53.45 \pm 0.19 a$ & $7.02 \pm 0.06 a$ & $54.08 \pm 0.23 b$ & $26.33 \pm 0.83 b$ & $3.05 \pm 0.07 a$ & $72.53 \pm 1.25 a$ & $12.57 \pm 0.21 a$ \\
\hline $\mathrm{FR}$ & $53.20 \pm 0.42 a$ & $7.23 \pm 0.05 a$ & $57.56 \pm 0.48 a$ & $25.17 \pm 0.32 b$ & $2.75 \pm 0.02 b$ & $66.17 \pm 1.68 \mathrm{~b}$ & $11.48 \pm 0.12 b$ \\
\hline UF & $51.91 \pm 2.09 a$ & $7.06 \pm 0.21 a$ & $54.59 \pm 0.51 b$ & $27.01 \pm 0.53 b$ & $2.79 \pm 0.09 b$ & $64.24 \pm 1.30 b$ & $12.01 \pm 0.27 a b$ \\
\hline
\end{tabular}

Data represent mean $\pm S E(n=12)$. Means followed by different letters were significantly different at $p<0.05$, according to Ducan's multiple range test.

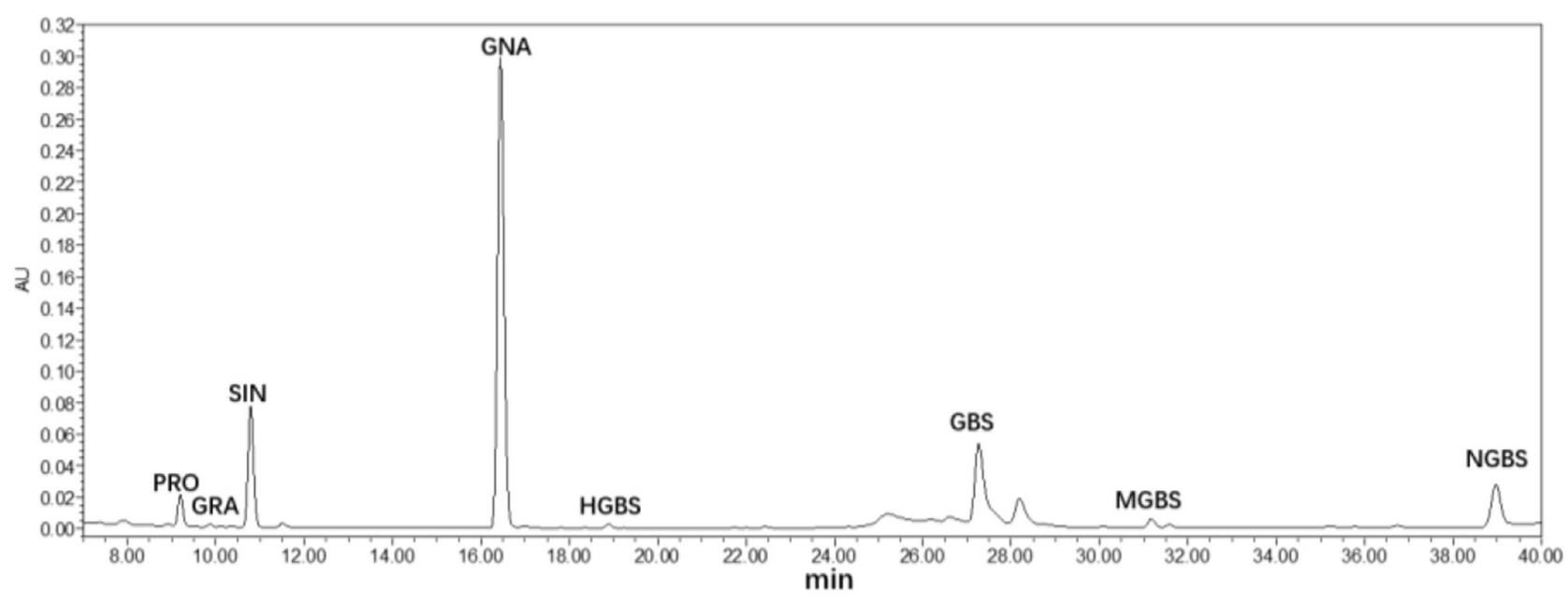

FIGURE 4 | HPLC chromatograms (290 nm) of glucosinolates in Chinese kale baby leaves.

contributed to the enhancement of GNA and SIN accumulation. However, FR had opposite effects that decreased the contents of total and aliphatic GLs, while no striking different or a reduction trend was found in UF.

\section{Heatmap Analysis of Growth and Nutritional Aspects of Chinese Kale Baby Leaves Under Supplemental UV-A and FR Light}

To gain an integrated view on agronomic traits, a nutritional and functional profile of Chinese kale baby leaves in response to UV-A and FR radiation, the heatmap synthesized was performed (Figure 6). The results demonstrated that four treatments could be divided into two clusters; the first group contained CK and UV-A, characterized by higher contents of glucosinolates, flavonoids, polyphenols, while lower growth-related parameters, especially under CK. FR, and UF displayed higher plant dry and fresh weight, leaf area, petiole length, and main stem length than CK and UV-A. Thus, UV-A was benefited for improving the functional components of Chinese kale baby leaves, while UF and FR were propitious to growth of Chinese kale baby leaves.

\section{Effects of Supplementary UV-A and FR Lights on Light-Signaling Components of Chinese Kale Baby Leaves}

To gain further insights into what changes induced by UV-A and FR radiation in light-signaling pathways, the expressions of genes encoding PHYs, CRYs, and UVR8 and PIFs in Chinese kale baby leaves at 6 days were analyzed. Interestingly, similar gene expression patterns were observed for CRY1, PHOT1, and PHYC, where the expression did not differ significantly in FR and UF, but markedly higher transcript levels in UV-A than CK (Figure 7; Supplementary Figure 2). FR elevated the expression level of CRY2 and PHOT2, but UF decreased the expression level of CYR2, PHOT2, and PHYE. Both FR and UF significantly elevated the expression level of $P H Y B$. Moreover, $P H Y A$ displayed a higher expression level in FR than other treatments. However, the expressions of UVR8 did not show any difference in all treatments. These results implied that UV-A and FR regulated Chinese kale baby leaves growth by some special photoreceptors.

The expression of HY5 revealed a slight upregulation in UV-A, while decreased in UF. FR and UF lead to a marked upregulation in HFR1, while inhibited the expression of PIF1 (Figure 7; Supplementary Figure 3). PIF3 expressions decreased in all treatments, while PIF5 expression under UV-A observably 

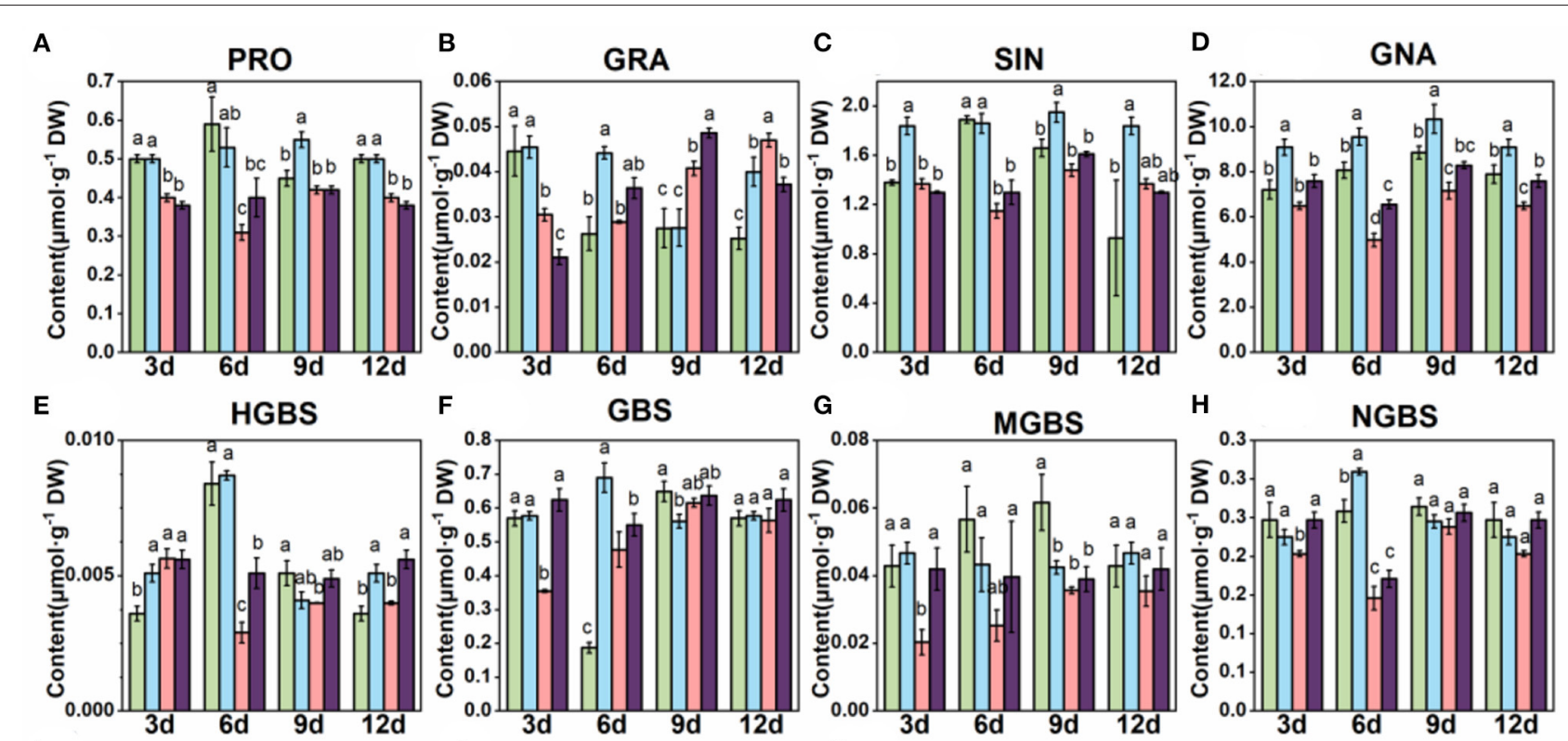

I Aliphatic glucosinolates
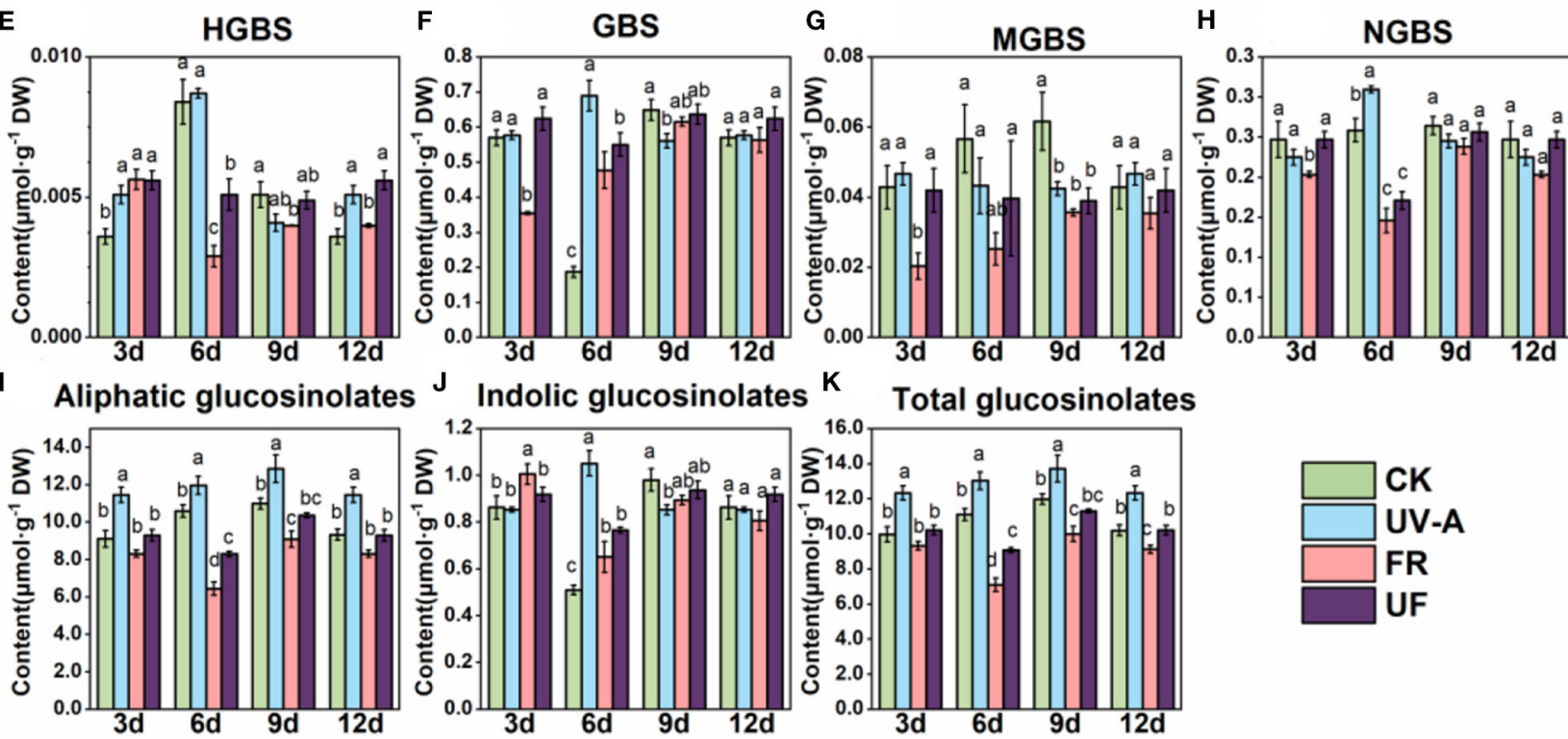

FIGURE 5 | The effect of supplemental UV-A and FR on glucosinolates composition and contents in shoots of Chinese kale baby leaves. The contents of (A) PRO, Progoitrin; (B) GRA, glucoraphanin; (C) SIN, sinigrin; (D) GNA, glucobrassicanapin; (E) HGBS, 4-hydroxy-glucobrassicin; (F) GBS, glucobrassicin; (G) MGBS, 4-methoxy-glucobrassicin; (H) NGBS, neoglucobrassicin; (I) individual aliphatic glucosinolates; (J) individual indolicglucosinolates; (K) total glucosinolates. Different letters on the top of the columns mean significant differences at $p<0.05$ according to Ducan's multiple range test.

exceeds other treatments (Figure 7; Supplementary Figure 3). Compared with CK, the expression of PIF4 was significantly upregulated under UV-A and FR, but no significant difference between CK and UF. The expression level of PIF5 significantly increased under UV-A; the lower expression level was found under FR and UF than CK (Figure 7; Supplementary Figure 3).

\section{Effects of Supplementary UV-A and FR Lights on the Transcript Levels of Genes Related to Glucosinolate Compound of Chinese Kale Baby Leaves}

The expressions of transcription factors and key genes involved in biosynthesis of glucosinolates in Chinese kale baby leaves were analyzed (Figure 7; Supplementary Figure 4). Similar gene expression patterns were observed for DOF1.1, MYB41, MYB28, and MYB34, where the expression levels were higher in Chinese kale baby leaves grown under UV-A than CK. Except that MYB76 expression was significantly upregulated under FR treatment, the expressions of DOF1.1, MYB41, MYB51, MYB28, and MYB34 were no significantly different or significantly downregulated under FR and UF.

The upregulated expressions by UV-A radiation were found in the majority of GLs biosynthesis-related genes in the chain elongation (BCAT4, IPMDH3, MAM1, and MAM3), core structure formation (CYP79F1, CYP83B1, GGP1, ST5a, ST5c, SUR1, and UGT74B1), as well as side chain modification (AOP2, AOP3, FMOGS-OX5, and GLS-OH) (Figure 7; Supplementary Figures 5, 6, 7). However, downregulated or unchanged expressions of GLs biosynthesis-related genes in Chinese kale baby leaves were observed in FR and UF.

\section{DISCUSSION}

\section{Effects of Supplementary UV-A and FR Light on the Plant Morphology and Biomass of Chinese Kale Baby Leaves}

Light is an essential external environmental factor playing decisive roles in regulating plant growth and development 


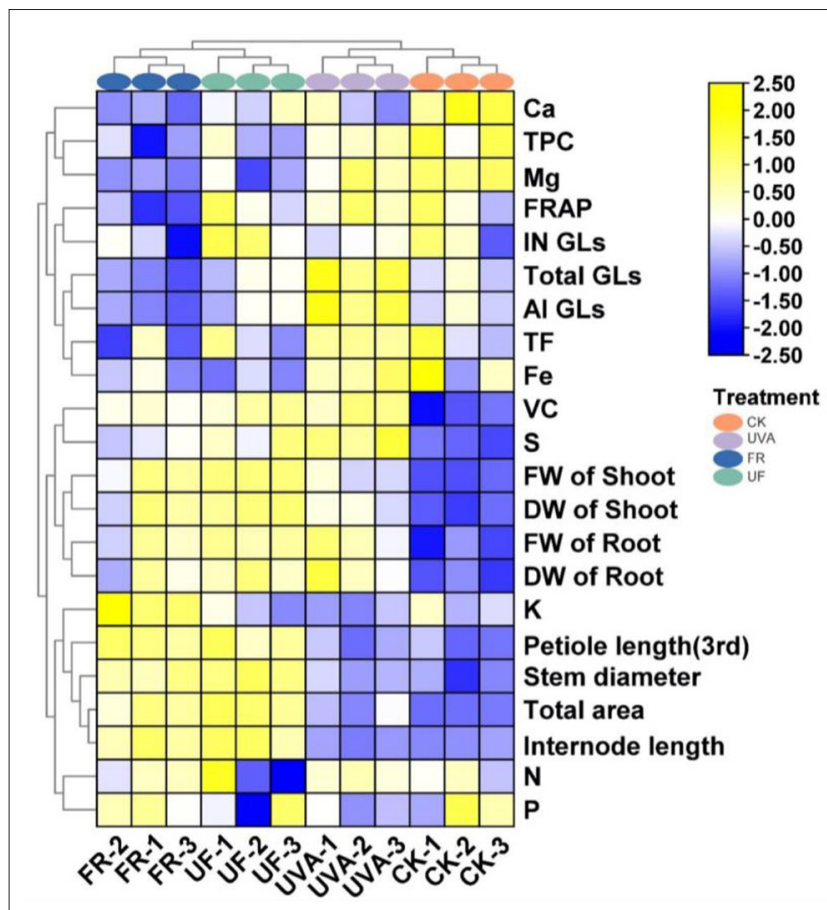

FIGURE 6 | Heatmap analysis summarized the effect of different supplemental UV-A intensities on growth and quality of Chinese kale baby leaves. Results were visualized using a false color scale, with yellow and blue indicating an increase and a decrease.

(Wong et al., 2020). Supplementary UV-A has been used as an efficient light source to meet the demand for higher health-promoting phytonutrients accumulating in horticultural products (Matsuura et al., 2013). Additionally, FR played predominant roles for the elongation of plant internodes and the increase of plant height and biomass (Park and Runkle, 2018; Zou et al., 2019). In the present study, UV-A exerted a suppressing effect on petiole length and the leaf area of Chinese kale baby leaves from 3 to 6 days (Figure 2). Interestingly, with the inhibitory effect gradually disappearing, UV-A was effective in stimulating overall plant growth at 12 days, resulting in a significant increase in growth-related parameters (Figures 2, 5). The promoting effects were consistent with other results that UV-A was positively associated with biomass production in many horticultural and agricultural crops (Chen et al., 2019; Lee et al., 2019). FR significantly promoted the elongation of plant stems and expansion of leaves due to the increasing of cells size, which was induced by FR radiation (De Wit et al., 2016). Thereby FR supplementation was benefit for plant to facilitate light interception and ultimately elicit better biomass production (Possart et al., 2014; Sheerin and Hiltbrunner, 2017). Morphology of Chinese kale baby leaves significantly affected by FR and UF from the third day of treatment, with the leaf area, main stem length, petiole length, as well as the fresh and dry weight of the plant was strikingly increasing (Figure 2). From cluster analysis (Figure 6), it directly indicated that application of UV-A and FR for vegetables might represent a valuable strategy to increase plant biomass.
The morphology and growth of plants responded to different light qualities via specific photoreceptors, which were closely related to downstream signaling transduction elements. CRYs, PHOTs, and UVR8 act as UV-A photoreceptors, which were involved in many plants physiological processes, such as stomatal opening, tropism, and hypocotyl elongation response. In this study, the expression of CRY1 and PHOTO1 in Chinese kale baby leaves under UV-A was higher than those of CK, while the expression of CRY2 and PHOTO2 did not show similar patterns (Figure 7; Supplementary Figure 2). Phytochromes, a group of receptors sensitive to FR light, have vital impacts on shoot and petiole elongation (Holopainen et al., 2018). PHYA and PHYB expressions were significantly upregulated under FR (Figure 7; Supplementary Figure 2). The promotion effects on plant growth and development under FR and UF might be attributed to the role of phytochromes in regulating the accumulation of various growth-promoting hormones, such as auxin, gibberellin, cytokinin, and brassinolide (Tao et al., 2008). The mechanistic understanding of how plants integrate complex photoreceptor and signaling network from different light environment needs to be investigated further.

Light-activated photoreceptors could move into the nucleus, where they interact with transcription factors, such as HY5, PIFs, and HFR1, ultimately regulating various light responses. PIF3 and PIF4 could mediate plant cell elongation and growth by positively regulating auxin biosynthesis and signaling (Al-Sady et al., 2006). Meanwhile, PIF4 takes part in signaling of the R/FR ratio in SAS response. In this study, PIF3 and PIF4 in Chinese kale baby leaves showed a significant upregulation under UF and FR, respectively (Figure 7; Supplementary Figure 3). Lowratio $\mathrm{R} / \mathrm{FR}$ light irradiation might reduce the activated state of PHYB; once the PIFs dissociated from the PHYB-PIF system, it combined with auxin synthesis-related genes to enhance the elongation of stems, petioles, and leaves (De Lucas et al., 2008; Feng et al., 2008). Higher expressions of HFR1 were significantly observed in FR and UF (Figure 7; Supplementary Figure 3). Interestingly, HFR1 could interact with PIF4 and PIF5, forming non-functional heterodimers that prevent PIFs binding to target genes by heterodimerization, therefore avoiding exaggerated shade avoiders (Tavridou et al., 2020).

It was worthwhile to note that lower photosynthetic pigments were induced by FR irradiation in several studies, whereas the photosynthetic rate increased, which might be contributed to the Emerson effect (Emerson et al., 1957; Bae et al., 2017). A previous study reported that chlorophyll contents in lettuce leaves increased under UV-A supplementation, while a downward trend was found in FR and UF, and the lowest chlorophyll content was under FR (He et al., 2021). A similar trend was also exhibited in the Chinese kale baby leaves (Supplementary Figure 8). The reduction of chlorophyll content in the Chinese kale baby leaves might be attributed to decreasing of $\mathrm{Ca}, \mathrm{Mg}$, and $\mathrm{Fe}$ contents under FR and UF treatments (Table 1), which play important roles in chlorophyll synthesis and photosynthesis in plants. Moreover, UF led to overall higher biomass production compared to other treatments (Figure 2), which was consisted with previous study that the combination of UV-A and FR 


\section{Light signaling components}

A
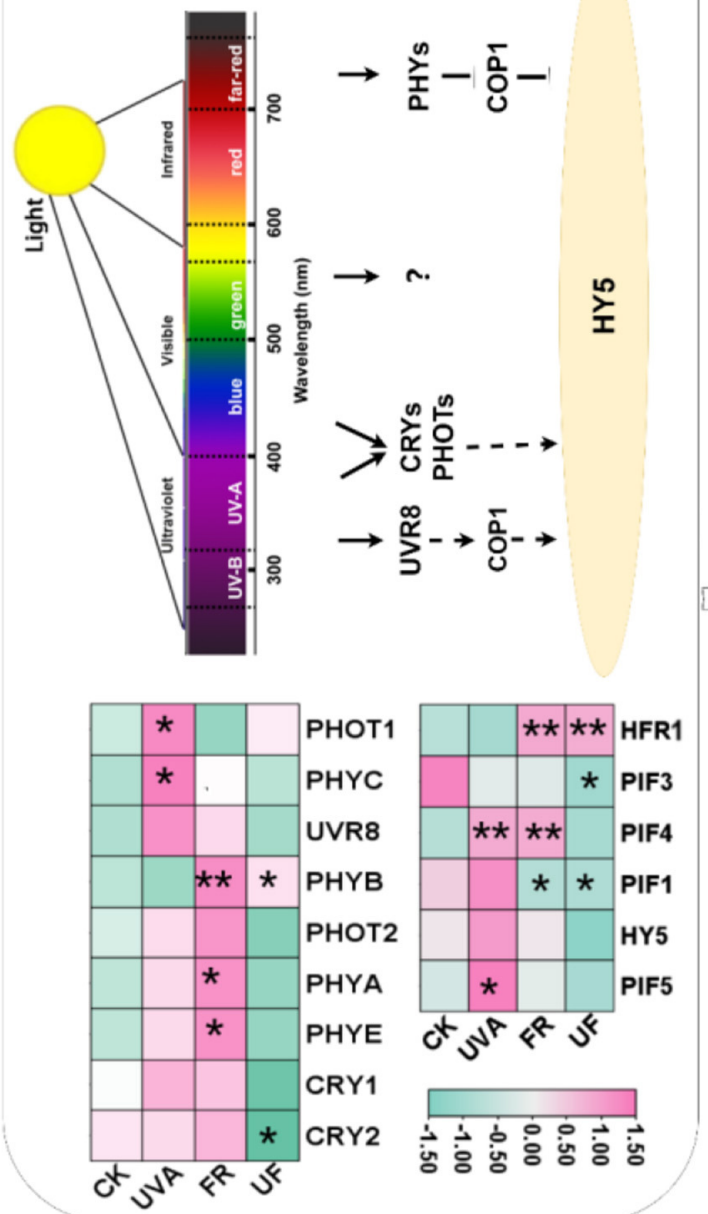

\section{Glucosinolate metabolism}

B

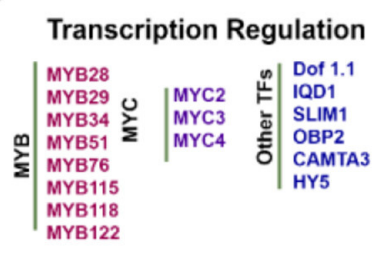
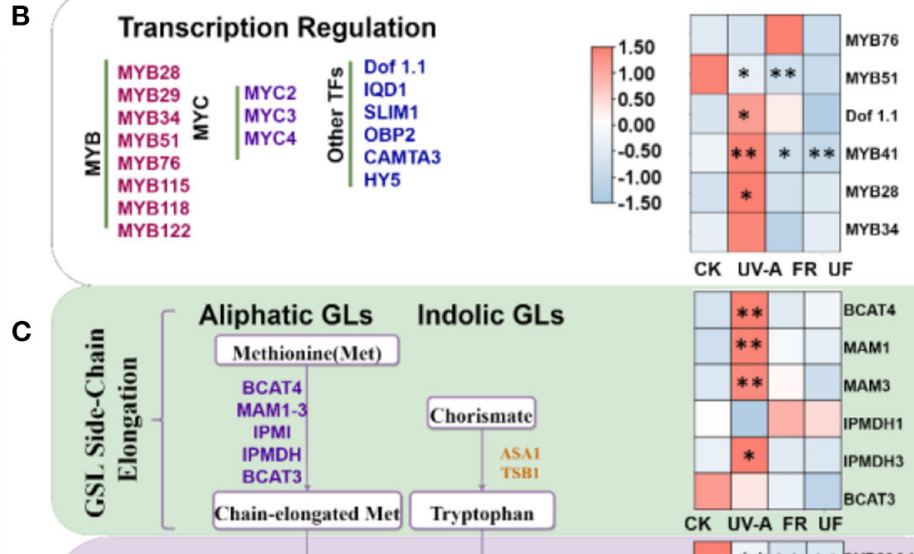

D
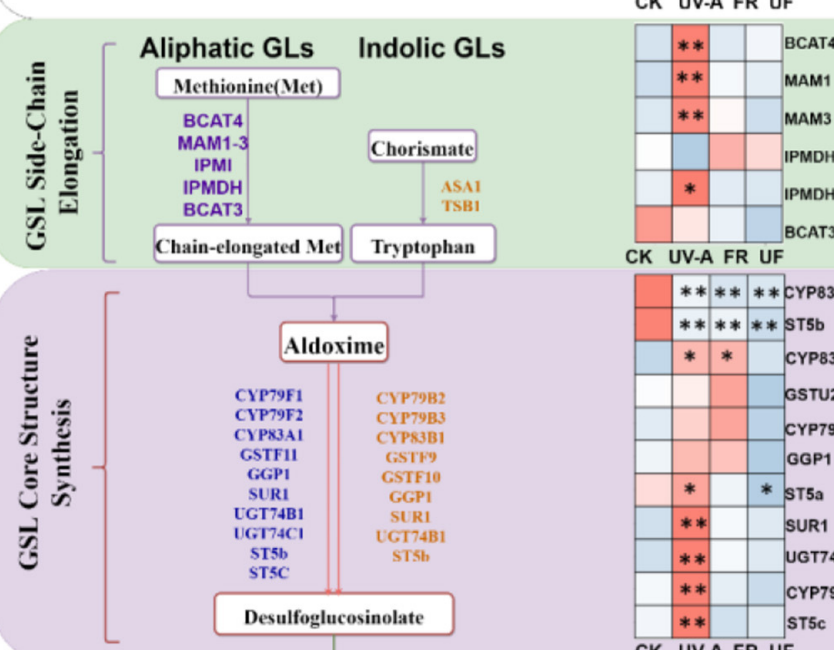

E

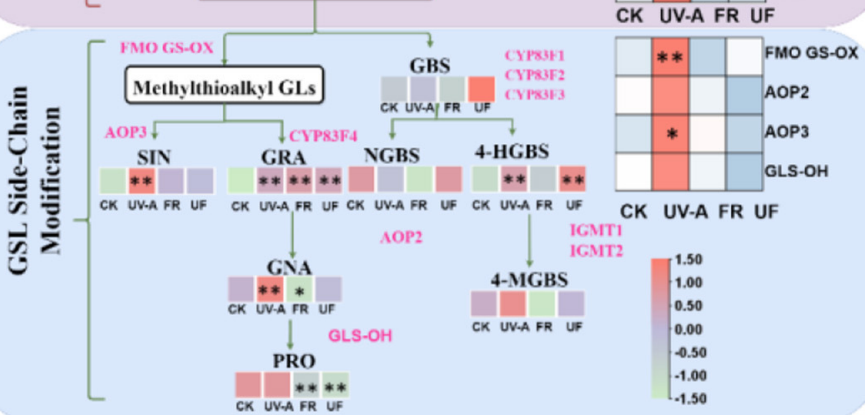

FIGURE 7 | The expression of related genes involved in glucosinolate biosynthesis in 6-day Chinese kale baby leaves grown under supplementary UV-A and FR. Five biosynthetic processes including (A) light signaling components; (B) the transcription factors involved in GLs biosynthesis; (C) chain elongation, (D) core structure formation, and (E) side-chain secondary modification were illustrated. *, ${ }^{\star \star}$ represent significant at $p<0.05, p<0.01, p<0.001$, respectively.

exhibited a remarkable increase in the biomass of lettuce ( $\mathrm{He}$ et al., 2021). These were consisted with that a combination of UV-A and FR exhibited a remarkable increase in the biomass of lettuce (He et al., 2021). These results indicated that UV-A and FR radiations exerted interactive and superimposing impacts on promoting Chinese kale baby leaves plants growth.

\section{Effects of Supplementary UV-A and FR Light on Healthy Functional Compound Contents of Chinese Kale Baby Leaves}

FRAP values and the contents of total phenols and flavonoids are usually used to evaluate total antioxidant capacity of vegetables. The linear relationship between the total antioxidant activity and the total phenolic content of Chinese kale baby leaves under supplementary UV-A and FR at 12 days is shown (Supplementary Figure 9). $R^{2}$ values from these correlations were high $\left(R^{2}>0.9\right)$; it was concluded that phenolic compounds were responsible for the antioxidant activity (Jacobo-Velázquez and Cisneros-Zevallos, 2009). Higher slopes were observed in UV-A and UF, which indicated that higher total phenolic content and total antioxidant activity in these treatments than CK and FR. Previous study showed that the FRAP value and contents of flavonoids and phenolics in red- and green-leaf pak-choi under supplementary UV-A $(380 \mathrm{~nm})$ were significantly higher than that under CK (Mao et al., 2020). However, FR and UF led to a reduction in levels of DPPH and FRAP and the content of anthocyanins, weakening antioxidant 
capacity of lettuce (He et al., 2021). In this study, antioxidants contents (total phenols, total flavonoids, and $\mathrm{Vc}$ ) and antioxidant capacity (FRAP) in Chinese kale baby leaves were generally improved by UV-A, while a decreasing trend was detected in FR (Figure 3). Compared with no light supplementation treatment, a $3.7 \mathrm{~W} \cdot \mathrm{m}^{-2} \mathrm{UV}$-A fluorescent lamp $\left(\lambda_{\max }=352 \mathrm{~nm}\right)$ supplemented for 3 days promoted the accumulation of total polyphenols in red leaf lettuce, increasing total antioxidant capacity (Lee et al., 2014). Moreover, UV-A upregulated the expression of transcription factor $M Y B$, key genes related to the phenylpropane metabolic pathway (e.g., $P A L, C H S$ ) by increasing the CRY1 and $H Y H$ transcription in plants, and ultimately promoted the accumulation of phenolic and flavonoids in the plants (Fuglevand et al., 1996; Guo and Wang, 2010; Zhang et al., 2013). The reduction in plant antioxidant capacity and antioxidant contents under FR radiation might be due to rapid increase in biomass of Chinese kale baby leaves, which led to the dilution of phytochemicals. Additionally, plants usually balance resource allocation between competing physiological activities (Huot et al., 2014). Plants under FR illumination dedicated most of the available resources to extend growth, reduce branching, and decrease production of some biochemical compounds, such as flavonoids and polyphenols. Therefore, substituting UV-A radiation, which was well-known as an available resource to enhance the accumulation of secondary metabolites and tailor functional features, could offset the negative effects induced by farred light.

\section{Supplementary UV-A and FR Influenced the Glucosinolates Accumulation by Affecting Genes Involved in Glucosinolates Biosynthesis of Chinese Kale Baby Leaves}

Glucosinolates are a class of secondary metabolites, which is effective in chemoprevention of cancers and degenerative diseases (Johnson, 2002). Light quality plays a vital role in the regulation of glucosinolates metabolism pathway in Brassicaceae vegetables. GNA and SIN, the predominant GLs in Chinese kale baby leaves, dramatically increased by UVA, attributing to an obvious increase in total aliphatic GLs and total GLs contents. Whereas, the accumulation GLs was restrained by FR (Figure 4), which was consisted with previous study that Chinese kale exposure under FR light showing a significant reduction inGLs profiles (Li et al., 2021). Interestingly, GLs contents under UF were higher than under FR but lower than under UV-A, although no obvious difference was found between UF and CK (Figure 4). The accumulations of 3-indolylmethyl glucosinolate, 4-methoxy-3-indolylmethyl glucosinolate, and 1-methoxy-3-indolylmethyl glucosinolate in Brussels sprouts were significantly enhanced by additional UVA radiation $(365 \mathrm{~nm})$ (Rechner et al., 2017). Similarly, 259 $\mathrm{kJm}{ }^{-2} \cdot \mathrm{d}^{-1}$ UV-A radiation was more effective than blue light in increasing the content of 3-methylindole glucosinolate in cabbage (Acharya et al., 2016). Supplementary UV-A to FR was efficient to compensate the reduction in GLs contents induced by FR (Figure 4). Therefore, the combined treatment contributed to higher antioxidant activity in UF compared to FR.

The biosynthesis of GLs can be divided into independent steps: (I) side-chain elongation of selected precursor amino acid, (II) formation of the core glucosinolates structure, and (III) secondary modifications of the side chain of core glucosinolates (Harun et al., 2020). Transcription factors act as important components of the regulatory network controlling glucosinolate biosynthesis. Overexpression of AtMYB28, AtMYB29, and $A t M Y B 76$ in Arabidopsis resulted in the production of large amounts of GLs, whereas AtMYB34, AtMYB51, and AtMYB122 specifically regulate indolic GLs formation (Celenza et al., 2005; Gigolashvili et al., 2007). Besides, IQD1 and AtDof.1 also played vital roles in the regulation of GLs biosynthesis (Gigolashvili et al., 2008). In this study, DOF1.1, MYB41, MYB28, and MYB34 expression levels were higher in Chinese kale baby leaves grown under UV-A, while a decreasing or unchanged tendency was found under FR and UF. These results indicated that UV-A and FR impacted the accumulation of GLs in Chinese kale baby leaves by affecting the transcription levels of transcription factors related to GLs synthesis.

The glucosinolate biosynthetic pathway involves multiple gene families, such as BCAT, MAM, CYP79, CYP83, and AOPs (Harun et al., 2020). UV-A upregulated expressions of genes related to glucosinolate side chain extension (BCAT4, IPMDH3, MAM1, and MAM3), core structural (CYP79F1, CYP83B1, ST5a, ST5c, SUR1, and UTG74B1), and secondary R side chain modification (AOP2, AOP3, FMOGS-OX5, and GLS$\mathrm{OH}$ ) (Figure 7), while no significant or opposite changes in these gene expression patterns of selected glucosinolate-related genes were observed in FR and UF (Figure 7). These revealed that key enzymes functioning upstream of desufo GLs were downregulated by supplementary FR, which might be correlated with the downregulation of the transcriptional activators $M Y B 28$, MYB28-like, and MYB51 (Li et al., 2021). Low R: FR ratios (0.55) effectively suppressed the accumulations of indolyl-3methyl glucosinolate and total indole GLs in Arabidopsis via inhibiting key genes involved in indole GLs biosynthesis, such as CYP79B2, CYP79B3, and CYP83B1/SUR2 (Celenza et al., 2005). In addition, our results also showed that sulfur contents were increased by all supplemental lights (Table 1), which indicated that sulfur might participate in GLs biosynthesis induced by light. Moreover, the GLs accumulation in plants does not only depend on their biosynthesis and the transport of GLs between organs, and the degradation of GLs in tissues also has a greater impact on the final total GLs content (Velasco et al., 2007; Wu et al., 2017). Therefore, alone or interactive effects of UV-A and FR on modulating GLs metabolism need to be further explored.

\section{CONCLUSIONS}

The morphological, physiological, and biochemical characteristics of Chinese kale baby leaves were altered by UV-A, FR, and UF radiation. FR light had a more positive 
impact than UV-A on the Chinese kale baby leaves growth, with a greater growth-related parameter, while it resulted in a reduction in the phytochemicals. UV-A displayed a remarkable effect on the contents of Vc, total phenolic, and flavonoid, as well as total aliphatic glucosinolates and total glucosinolates. Moreover, transcription factors (DOF1.1, MYB41, MYB28, and $M Y B 34)$ and genes related to cure structure of glucosinolates (BCATs, MAMs, CYP79s, CYP83s, and AOPs) and other gene families were upregulated under UV-A, which contributed to higher GLs accumulation in Chinese kale baby leaves. However, downregulated or unchanged expressions of GLs biosynthesisrelated genes in Chinese kale baby leaves were observed in FR and UF. Therefore, UV-A was benefited for the production of functional vegetables, while FR was conducive to a significant increase in crop yield. Supplemented with UV-A to FR seemed to be efficient to compensate the decrease in phytochemicals such as GLs contents induced by FR. Thus, the combination of UV-A and FR, as a balance between biomass production and the production of secondary metabolite, provided a new perspective for the application of artificial light in horticultural crop production.

\section{DATA AVAILABILITY STATEMENT}

The datasets presented in this study can be found in online repositories. The names of the repository/repositories and accession number(s) can be found in the article/Supplementary Material.

\section{AUTHOR CONTRIBUTIONS}

$\mathrm{RH}$ conceived, designed, and performed the experiments and wrote the manuscript. YL, SO, and MG performed the experiments and statistical analysis. YZ and SS were involved in the supervision of the experiments and analyzed the results. HL conceived and designed the experiments, analyzed the results, contributed to manuscript revision, and read and approved the submitted version. All the authors have read and approved the manuscript for publication.

\section{FUNDING}

This work was supported by a grant from the Key-Area Research and Development Program of Guangdong Province (2019B020214005 and 2019B020222003).

\section{SUPPLEMENTARY MATERIAL}

The Supplementary Material for this article can be found online at: https://www.frontiersin.org/articles/10.3389/fpls.2021. 799376/full\#supplementary-material

\section{REFERENCES}

Acharya, J., Rechner, O., Neugart, S., Schreiner, M., and Poehling, H. M. (2016). Effects of light-emitting diode treatments on Brevicoryne brassicae performance mediated by secondary metabolites in Brussels sprouts. J. Plant Dis. Prot. 123, 321-330. doi: 10.1007/s41348-0160029-9

Al-Sady, B., Ni, W., Kircher, S., Schäfer, E., and Quail, P. H. (2006). Photoactivated phytochrome induces rapid PIF3 phosphorylation prior to proteasomemediated degradation. Mol. Cell. 23, 439-446. doi: 10.1016/j.molcel.2006. 06.011

Bae, J. H., Park, S. Y., and Oh, M. M. (2017). Supplemental irradiation with far-red light-emitting diodes improves growth and phenolic contents in Crepidiastrum denticulatum in a plant factory with artificial lighting. Hortic. Environ. Biotechnol. 58, 357-366. doi: 10.1007/s13580-0170331-x

Benzie, I. F. F., and Strain, J. J. (1996). The ferric reducing ability of plasma (FRAP) as a measure of "antioxidant power": The FRAP assay. Anal. Biochem. 239, 70-76. doi: 10.1006/abio.1996.0292

Celenza, J. L., Quiel, J. A., Smolen, G. A., Merrikh, H., Silvestro, A. R., Normanly, J., et al. (2005). The arabidopsis ATR1 Myb transcription factor controls indolic glucosinolate homeostasis. Plant Physiol. 137, 253-262. doi: 10.1104/pp.104.054395

Chen, C., Chen, H., Zhang, Y., Thomas, H. R., Frank, M. H., He, Y., et al. (2020). TBtools: an integrative toolkit developed for interactive analyses of big biological data. Mol. Plant. 13, 1194-1202. doi: 10.1016/j.molp.2020. 06.009

Chen, Y., Li, T., Yang, Q., Zhang, Y., Zou, J., Bian, Z., et al. (2019). UVA radiation is beneficial for yield and quality of indoor cultivated lettuce. Front. Plant Sci. 10:1563. doi: 10.3389/fpls.2019. 01563

De Lucas, M., Davière, J. M., Rodríguez-Falcón, M., Pontin, M., Iglesias-Pedraz, J. M., Lorrain, S., et al. (2008). A molecular framework for light and gibberellin control of cell elongation. Nature. 451, 480-484. doi: 10.1038/nature06520

De Wit, M., Galvão, V. C., and Fankhauser, C. (2016). Light-mediated hormonal regulation of plant growth and development. Annu. Rev. Plant Biol. 67, 513-537. doi: 10.1146/annurev-arplant-043015-112252

Emerson, R., Chalmers, R., and Cederstrand, C. (1957). Some factors influencing the long-wave limit of photosynthesis. Proc. Natl. Acad. Sci. USA. 43, 133-143. doi: 10.1073/pnas.43.1.133

Feng, S., Martinez, C., Gusmaroli, G., Wang, Y., Zhou, J., Wang, F., et al. (2008). Coordinated regulation of Arabidopsis thaliana development by light and gibberellins. Nature 451, 475-479. doi: 10.1038/nature 06448

Fuglevand, G., Jackson, J. A., and Jenkins, G. I. (1996). Physiologists UV-B, UV-A, and blue light signal transduction pathways interact synergistically to regulate chalcone synthase gene expression in Arabidopsis. Plant Cell 8, 2347-2357. doi: 10.1105/tpc.8.12.2347

Fukuyama, T., Ohashi-Kaneko, K., Hirata, K., Muraoka, M., and Watanabe, H. (2017). Effects of ultraviolet a supplemented with red light irradiation on vinblastine production in Catharanthus roseus. Environ. Control Biol. 55, 65-69. doi: 10.2525/ecb.55.65

Galvão, V. C., and Fankhauser, C. (2015). Sensing the light environment in plants: photoreceptors and early signaling steps. Curr. Opin. Neurobiol. 34, 46-53. doi: 10.1016/j.conb.2015.01.013

Gao, M., He, R., Shi, R., Li, Y., Song, S., Zhang, Y., et al. (2021). Combination of selenium and UVA radiation affects growth and phytochemicals of broccoli microgreens. Molecules 26:4646. doi: 10.3390/molecules261 54646

Gigolashvili, T., Berger, B., Mock, H. P., Müller, C., Weisshaar, B., and Flügge, U. I. (2007). The transcription factor HIG1/MYB51 regulates indolic glucosinolate biosynthesis in Arabidopsis 
thaliana. Plant J. 50, 886-901. doi: 10.1111/j.1365-313X.2007.03 099.x

Gigolashvili, T., Engqvist, M., Yatusevich, R., Müller, C., and Flügge, U. I. (2008). HAG2/MYB76 and HAG3/MYB29 exert a specific and coordinated control on the regulation of aliphatic glucosinolate biosynthesis in Arabidopsis thaliana. New Phytol. 177, 627-642. doi: 10.1111/j.1469-8137.2007.0 2295.x

Guo, J., and Wang, M. H. (2010). Ultraviolet A-specific induction of anthocyanin biosynthesis and PAL expression in tomato (Solanum lycopersicum L.). Plant Growth Regul.62, 1-8. doi: 10.1007/s10725-010-9472-y

Harun, S., Abdullah-Zawawi, M. R., Goh, H. H., and Mohamed-Hussein, Z. A. (2020). A comprehensive gene inventory for glucosinolate biosynthetic pathway in Arabidopsis thaliana. J. Agric. Food Chem. 68, 7281-7297. doi: 10.1021/acs.jafc.0c01916

He, R., Zhang, Y., Song, S., Su, W., Hao, Y., and Liu, H. (2021). UV$A$ and FR irradiation improves growth and nutritional properties of lettuce grown in an artificial light plant factory. Food Chem. 345:128727. doi: 10.1016/j.foodchem.2020.128727

Holopainen, J. K., Kivimäenp,ää, M., and Julkunen-Tiitto, R. (2018). New light for phytochemicals. Trends Biotechnol. 36, 7-10. doi: 10.1016/j.tibtech.2017.08.009

Huot, B., Yao, J., Montgomery, B. L., and He, S. Y. (2014). Growth-defense tradeoffs in plants: a balancing act to optimize fitness. Mol. Plant. 7, 1267-1287. doi: 10.1093/mp/ssu049

Jacobo-Velázquez, D. A., and Cisneros-Zevallos, L. (2009). Correlations of antioxidant activity against phenolic content revisited: a new approach in data analysis for food and medicinal plants. J. Food Sci. 74,107-113. doi: 10.1111/j.1750-3841.2009.01352.x

Ji, Y., Nuñez Ocaña, D., Choe, D., Larsen, D. H., Marcelis, L. F. M., and Heuvelink, E. (2020). Far-red radiation stimulates dry mass partitioning to fruits by increasing fruit sink strength in tomato. New Phytol.228, 1914-1925. doi: $10.1111 / \mathrm{nph} .16805$

Johnson, I. T. (2002). Glucosinolates in the human diet. Bioavailability and implications for health. Phytochem. Rev. 1, 183-188. doi: 10.1023/A:1022507300374

Jung, W. S., Chung, I. M., Hwang, M. H., Kim, S. H., Yu, C. Y., and Ghimire, B. K. (2021). Application of light-emitting diodes for improving the nutritional quality and bioactive compound levels of some crops and medicinal plants. Molecules 26:1477. doi: 10.3390/molecules26051477

Kampfenkel, K., Van Montagu, M., and Inz,é, D. (1995). Extraction and determination of ascorbate and dehydroascorbate from plant tissue. Anal. Biochem. 225, 165-167. doi: 10.1006/abio.1995.1127

Kapusta-Duch, J., Kopeć, A., Piatkowska, E., Borczak, B., and Leszczyńska, T. (2012). The beneficial effects of Brassica vegetables on human health. Rocz. Państwowego Zakładu Hig. 63, 389-395.

Karpiński, S., Szechyńska-Hebda, M., Wituszyńska, W., and Burdiak, P. (2013). Light acclimation, retrograde signalling, cell death and immune defences in plants. Plant Cell Environ. 36, 736-744. doi: 10.1111/pce. 12018

Lee, J. H., Oh, M. M., and Son, K. H. (2019). Short-term ultraviolet (UV)A light-emitting diode (LED) radiation improves biomass and bioactive compounds of kale. Front. Plant Sci. 10:1042. doi: 10.3389/fpls.2019. 01042

Lee, M. J., Son, J. E., and Oh, M. M. (2014). Growth and phenolic compounds of Lactuca sativa L. grown in a closed-type plant production system with UV-A, -B, or -C lamp. J. Sci. Food Agric. 94, 197-204. doi: 10.1002/jsfa.6227

Legendre, R., and van Iersel, M. W. (2021). Supplemental far-red light stimulates lettuce growth: Disentangling morphological and physiological effects. Plants 10, 1-21. doi: 10.3390/plants10010166

Li, Y., Gao, M., He, R., Zhang, Y., Song, S., Su, W., et al. (2021). Far-red light suppresses glucosinolate profiles of Chinese kale through inhibiting genes related to glucosinolate biosynthesis. Environ. Exp. Bot. 188:104507. doi: 10.1016/j.envexpbot.2021.104507

Li, Y., Shi, R., Jiang, H., Wu, L., Zhang, Y., Song, S., et al. (2020a). End-of-day led lightings influence the leaf color, growth and phytochemicals in two cultivars of lettuce. Agronomy 10:1475. doi: 10.3390/agronomy10101475

Li, Y., Zheng, Y., Zheng, D., Zhang, Y., Song, S., Su, W., et al. (2020b). Effects of supplementary blue and UV-A LED lights on morphology and phytochemicals of Brassicaceae baby-leaves. Molecules 25, 56-78. doi: 10.3390/molecules25235678

Livak, K. J., and Schmittgen, T. D. (2001). Analysis of relative gene expression data using real-time quantitative PCR and the $2^{-\Delta \Delta C T}$ method. Methods 25, 402-408. doi: 10.1006/meth.2001.1262

Mao, P., Duan, F., Zheng, Y., and Yang, Q. (2020). Blue and UV-A light wavelengths positively affected accumulation profiles of healthy compounds in pak-choi. J. Sci. Food Agric. 101, 1676-1684. doi: 10.1002/jsfa.10788

Mariz-Ponte, N., Mendes, R. J., Sario, S., Melo, P., and Santos, C. (2018). Moderate UV-A supplementation benefits tomato seed and seedling invigoration: a contribution to the use of UV in seed technology. Sci. Hortic. 235, 357-366. doi: 10.1016/j.scienta.2018.03.025

Matsuura, H. N., De Costa, F., Yendo, A. C. A., and Fett-Neto, A. G. (2013). Photoelicitation of bioactive secondary metabolites by ultraviolet radiation: mechanisms, strategies, and applications. Biotechnol. Med. Plants 7, 171-190. doi: 10.1007/978-3-642-29974-2_7

Neugart, S., and Schreiner, M. (2018). UVB and UVA as eustressors in horticultural and agricultural crops. Sci. Hortic. 234, 370-381. doi: 10.1016/j.scienta.2018.02.021

Park, Y., and Runkle, E. S. (2018). Far-red radiation and photosynthetic photon flux density independently regulate seedling growth but interactively regulate flowering. Environ. Exp. Bot. 155, 206-216. doi: 10.1016/j.envexpbot.2018.06.033

Possart, A., Fleck, C., and Hiltbrunner, A. (2014). Shedding (far-red) light on phytochrome mechanisms and responses in land plants. Plant Sci. 316, 36-46. doi: 10.1016/j.plantsci.2013.11.013

Qian, H., Liu, T., Deng, M., Miao, H., Cai, C., Shen, W., et al. (2016). Effects of light quality on main health-promoting compounds and antioxidant capacity of Chinese kale sprouts. Food Chem. 196, 1232-1238. doi: 10.1016/j.foodchem.2015.10.055

Rechner, O., Neugart, S., Schreiner, M., Wu, S., and Poehling, H. M. (2017). Can narrow-bandwidth light from UV-A to green alter secondary plant metabolism and increase Brassica plant defenses against aphids? PLoS ONE. 12:188522. doi: 10.1371/journal.pone.0188522

Saijo, Y., Sullivan, J. A., Wang, H., Yang, J., Shen, Y., Rubio, V., et al. (2003). The COP1-SPA1 interaction defines a critical step in phytochrome A-mediated regulation of HY5 activity. Genes Dev. 17, 2642-2647. doi: 10.1101/gad.1122903

Sheerin, D. J., and Hiltbrunner, A. (2017). Molecular mechanisms and ecological function of far-red light signalling. Plant Cell Environ. 40, 2509-2529. doi: 10.1111/pce.12915

Steindal, A. L. H., Johansen, T. J., Bengtsson, G. B., Hagen, S. F., and Mølmann, J. A. B. (2016). Impact of pre-harvest light spectral properties on healthand sensory-related compounds in broccoli florets. J. Sci. Food Agric. 96, 1974-1981. doi: 10.1002/jsfa.7307

Tang, Y., Mao, R., and Guo, S. (2020). Effects of LED spectra on growth, gas exchange, antioxidant activity and nutritional quality of vegetable species. Life Sci. Sp. Res. 26, 77-84. doi: 10.1016/j.lssr.2020.05.002

Tao, Y., Ferrer, J. L., Ljung, K., Pojer, F., Hong, F., Long, J. A., et al. (2008). Rapid synthesis of auxin via a new tryptophan-dependent pathway is required for shade avoidance in plants. Cell 133, 164-176. doi: 10.1016/j.cell.2008.01.049

Tavridou, E., Schmid-Siegert, E., Fankhauser, C., and Ulm, R. (2020). UVR8mediated inhibition of shade avoidance involves HFR1 stabilization in Arabidopsis. PLoS Genet. 16:e1008797. doi: 10.1371/journal.pgen.1008797

Velasco, P., Cartea, M. E., González, C., Vilar, M., and Ordás, A. (2007). Factors affecting the glucosinolate content of kale (Brassica oleracea acephala Group). J. Agric. Food Chem. 55, 955-962. doi: 10.1021/jf0624897

Waterland, N. L., Moon, Y., Tou, J. C., Kim, M. J., Pena-Yewtukhiw, E. M., and Park, S. (2017). Mineral content differs among microgreen, baby leaf, and adult stages in three cultivars of Kale. HortScience. 52, 566-571. doi: 10.21273/HORTSCI11499-16

Wong, C. E., Teo, Z. W. N., Shen, L., and Yu, H. (2020). Seeing the lights for leafy greens in indoor vertical farming. Trends Food Sci. Technol. 106, 48-63. doi: 10.1016/j.tifs.2020.09.031

Wu, S., Lei, J., Chen, G., Chen, H., Cao, B., and Chen, C. (2017). De novo transcriptome assembly of chinese kale and global expression analysis of genes involved in glucosinolate metabolism in multiple tissues. Front. Plant Sci. 8:92. doi: 10.3389/fpls.2017.00092 
Xie, Y., Zheng, Y., Dai, X., Wang, Q., Cao, J., and Xiao, J. (2015). Seasonal dynamics of total flavonoid contents and antioxidant activity of Dryopteris erythrosora. Food Chem. 186, 113-118. doi: 10.1016/j.foodchem.2014. 05.024

Zhang, Y., Kaiser, E., Zhang, Y., Zou, J., Bian, Z., Yang, Q., et al. (2020). UVA radiation promotes tomato growth through morphological adaptation leading to increased light interception. Environ. Exp. Bot. 176:104073. doi: 10.1016/j.envexpbot.2020.1 04073

Zhang, Z. Z., Che, X. N., Pan, Q. H., Li, X. X., and Duan, C. Q. (2013). Transcriptional activation of flavan-3-ols biosynthesis in grape berries by UV irradiation depending on developmental stage. Plant Sci. 208, 64-74. doi: 10.1016/j.plantsci.2013. 03.013

Zou, J., Zhang, Y. Y., Zhang, Y. Y., Bian, Z., Fanourakis, D., Yang, Q., et al. (2019). Morphological and physiological properties of indoor cultivated lettuce in response to additional far-red light. Sci. Hortic. 257:108725. doi: 10.1016/j.scienta.2019.108725
Conflict of Interest: The authors declare that the research was conducted in the absence of any commercial or financial relationships that could be construed as a potential conflict of interest.

Publisher's Note: All claims expressed in this article are solely those of the authors and do not necessarily represent those of their affiliated organizations, or those of the publisher, the editors and the reviewers. Any product that may be evaluated in this article, or claim that may be made by its manufacturer, is not guaranteed or endorsed by the publisher.

Copyright (c) $2021 \mathrm{He}, \mathrm{Li}, \mathrm{Ou}, \mathrm{Gao}$, Zhang, Song and Liu. This is an open-access article distributed under the terms of the Creative Commons Attribution License (CC $B Y)$. The use, distribution or reproduction in other forums is permitted, provided the original author(s) and the copyright owner(s) are credited and that the original publication in this journal is cited, in accordance with accepted academic practice. No use, distribution or reproduction is permitted which does not comply with these terms. 